\title{
PERANCANGAN BAK PRASEDIMENTASI
}

\author{
R. Esther Ambat ${ }^{1}$, R. Andjar Prasetyo ${ }^{1}$ \\ ${ }^{1}$ Staf Pengajar Jurusan Teknik Sipil Politeknik Negeri Bandung Jl. Gegerkalong Hilir Ds.Ciwaruga \\ Bandung 40012. Email: esther_ambat@yahoo.com
}

\begin{abstract}
ABSTRAK
Sistem penyediaan air minum harus dapat menyediakan air yang memadai dari segi kualitas maupun kuantitas. Fungsi utama dari bangunan bak prasedimentasi (Plain Sedimentation Basins) adalah untuk menghilangkan/mencegah gravel, pasir, lumpur, maupun material kasar lainnya agar tidak masuk ke dalam Instalasi Pengolahan Air (IPA). Bila kecepatan aliran masuk pada saluran (V) $60 \mathrm{~cm} /$ detik, debit yang diolah $(\mathrm{Q}) \quad 0,15 \mathrm{~m}^{3} /$ detik, maka penyisihan tingkat kekeruhan yang optimal diperoleh dari bak prasedimentasi dengan dimensi: panjang 12 meter, lebar 6,7 meter dan tinggi 1,75 meter, dengan syarat pembuangan lumpur harus dilakukan secara periodik dan teratur sesuai dengan perencanaan, yaitu setiap 3 hari. Aliran air harus dijaga agar tetap tenang /tidak bergejolak (laminer) sehingga tidak mengganggu proses pengendapan secara gravitasi.
\end{abstract}

Kata kunci: air baku, pengolahan, prasedimentasi.

\section{Pendahuluan}

Sumber air baku yang diambil dari sungai pada umumnya harus melalui sistem pengolahan lengkap (Complete Treatment Plant) terlebih dahulu. Salah satu bentuk pengolahan air baku dalam pengolahan lengkap adalah unit prasedimentasi. Dibutuhkan perhitungan yang matang pada proses prasedimentasi ini, agar kerja unit pengolahan berikutnya dapat optimal.

Tujuan dari tulisan ini adalah memberikan suatu contoh konkrit cara merancang unit prasedimentasi guna mengurangi beban proses pengolahan berikutnya.

Ruang lingkup dari tulisan ini adalah membuat suatu rancangan unit prasedimentasi pada sistem pengolahan air minum.

\section{Studi Pustaka}

Material kasar (partikel diskrit) dapat terbawa dalam air baku oleh proses penggerusan secara alami dari arus air sepanjang aliran badan sungai, baik pada dinding maupun dasarnya. Hal ini juga dapat terjadi karena penggerusan tanah di luar badan sungai yang kemudian masuk ke dalamnya dan biasanya kandungan material kasar ini akan menjadi tinggi pada saat aliran deras, yaitu pada saat musim penghujan. Material kasar ini mempunyai efek yang kurang baik apabila masuk kedalam sistem pengolahan, terutama pada unit-unit peralatan mekanik, karena dapat mengganggu kerja unit-unit tersebut. Pasir dan lumpur disamping dapat menyumbat pompa, material inipun dapat merusak unit yang bergerak dan terendam di dalam air seperti bagian impeller pompa.

Fungsi utama dari bangunan bak prasedimentasi (Plain Sedimentation Basins) adalah untuk menghilangkan/mencegah gravel, pasir, lumpur maupun material kasar lainnya agar tidak masuk kedalam Instalasi Pengolahan Air (IPA) Dengan dibangunnya prasedimentasi pada suatu sistem pengolahan air minum, material kasar yang terbawa oleh air baku dapat direduksi sampai ke tingkat minimal sesuai dengan rancang bangun yang akan diterapkan. 


\section{Sistem Prasedimentasi}

Sistem prasedimentasi secara garis besar dapat dibagi menjadi 3 (tiga) jenis, yaitu:

- Prasedimentasi dengan pengendapan secara alami (gravitasi)

- Sand-traps (Penjebak Pasir).

- Prasedimentasi mekanik, untuk menghilangkan pasir dan kerikil.

2. Prasedimentasi dengan pengendapan secara alami

Material yang kasar mempunyai berat jenis lebih besar dari pada air, material ini pasti akan jatuh/ mengendap ke bagian dasar. Material ini dapat terbawa arus air (melayang) sebagai akibat daya jatuhnya dikalahkan oleh gaya dorong arus air.

Bak prasedimentasi umumnya dibuat memanjang searah aliran air, pada saat air masuk ke dalam bak maka kecepatan arusnya menjadi berkurang. Karena luas penampang bak yang tegak lurus aliran biasanya lebih besar dari saluran masuknya, material-material yang berat akan segera jatuh pada bagian muka bak.

3. Kriteria perencanaan unit prasedimentasi:

$\mathrm{V}_{0}=$ kecepatan mengendap dari partikel ideal: $0,08-0,1 \mathrm{~cm} /$ detik

$t_{d}=$ waktu pengendapan: $0,5-3 \mathrm{jam}$

Kondisi aliran $\mathrm{N}_{\mathrm{RE}}<2000$ dan $\mathrm{N}_{\mathrm{Fr}}>10^{-5}$

$\mathrm{V}_{\mathrm{h}}=(10-18) \mathrm{V}_{0}$

$\frac{t}{t d}=\frac{V_{0}}{Q / A}$

Keterangan:

$t=$ design detention time

$t d=$ theoritical detention time, atau dengan menggunakan persamaan:

$$
\frac{y}{y_{0}}=1-\left(1+\frac{n V_{0}}{Q / A}\right)^{-1 / n}
$$

Keterangan:

$y=$ Removal (pemisahan) yang diharapkan

$y_{0}=$ Removal ideal

$n=$ Angka performance

$V_{0}=$ Kecepatan mengendap partikel

$Q / A=$ Beban permukaan (Surface loading)
Perhitungan panjang bak menggunakan persamaan sebagai berikut:

Panjang bak $(\mathrm{P})=\mathrm{V}_{\mathrm{h}} \mathrm{x}$

Keterangan:

$\mathrm{V}_{\mathrm{h}}=$ kecepatan horizontal

$\mathrm{t}$ = waktu pengendapan

Untuk mengontrol kondisi aliran digunakan persamaan sebagai berikut:

$$
\begin{aligned}
& N_{\mathrm{Re}}=V h x \frac{R}{v} \leq 2000 \\
& N_{F r}=\frac{V h^{2}}{(g x R)} \geq 10^{-5}
\end{aligned}
$$

Untuk mengecek NRe partikel digunakan hukum Stoke dengan persamaan sebagai berikut:

$V s=\frac{1}{18}\left[\frac{(S s-1)}{\delta}\right] \cdot g \cdot d^{2}$

Untuk mengontrol terhadap kecepatan penggerusan (scouring) digunakan persamaan sebagai berikut:

$V_{S c}=\sqrt{\frac{8 \beta}{\lambda} \cdot \frac{\rho_{s}-\rho_{w}}{\rho_{w}} \cdot g \cdot d}$

(L. Huisman, Sedimentation And Flotation).

Keterangan:

$V_{S c}=$ kecepatan scouring

$\lambda=$ faktor gesekan hidrolis $(0,03)$

$\beta=0,04$ Unigrnulair Sand 0,06 Non Uniform

diambil rata - rata $=0,03$

$\mathrm{g}=$ gravitasi

$\mathrm{d}=$ diameter partikel

$\rho_{\mathrm{S}}=$ berat jenis partikel

$\mathrm{w}=$ berat jenis air $=1$

\section{Ruang penyimpanan lumpur}

Perhitungan volume lumpur diambil dari suatu percobaan dengan menggunakan tabung Inhoff Cone dengan tujuan untuk mengetahui prosentase pengendapan lumpur dalam selang waktu yang ditentukan kemudian direncanakan periode buang lumpur $\left(V_{\text {lumpur }}\right)$, persamaan yang digunakan adalah:

$V_{\text {Lumpur }}=Q x \%_{\text {Pengendapan }} x t_{B L}$ 
Keterangan:

$\mathrm{Q}=$ Kapasitas produksi (1/detik)

$\%$ pengendapan $=$ dari percobaan Inhoff Cone

$\mathrm{t}=$ Waktu penyimpanan lumpur (hari)

Sedangkan untuk perhitungan ruang lumpur digunakan persamaan:

$V_{\text {Luimas }}=\frac{1}{3} x t x A_{\text {Surface }} \rightarrow V_{\text {Lumpur }} \cong V_{\text {Luimas }}$

A surface $=$ luas permukaan bak prasedimentasi.

\section{Pintu air}

Kehilangan tekanan (hf) menentukan luas pintu air (Acr) dan kecepatan aliran (V) pada pintu air. Kehilangan tekanan pada Pintu dihitung dengan rumus:

$$
h_{f}=\left(\frac{Q}{2,746 x b x h}\right)^{2}
$$

Keterangan:

$\mathrm{Q}=$ Kapasitas produksi (1/detik)

$\mathrm{h} f=$ kehilangan tekanan $(\mathrm{cm})$

$\mathrm{b}=$ lebar saluran $(\mathrm{cm})$

$\mathrm{h}=$ tinggi bukaan pintu $(\mathrm{cm})$

Luas Pintu (Acr)

$$
\begin{aligned}
& Q=C \cdot A \cdot \sqrt{2 \cdot g \cdot h} \rightarrow C=0,6 \\
& A c r=\frac{Q}{C \cdot \sqrt{2 \cdot g \cdot h_{1}}} \ldots \ldots \ldots \ldots \ldots \ldots
\end{aligned}
$$

Kecepatan aliran (V)

$\mathrm{V}=C \cdot \sqrt{2 \cdot g \cdot h_{1}}$

\section{Pemerataan aliran}

Untuk pemerataan aliran yang masuk ke ruang zona pengendapan dapat digunakan dinding berlubang (perporated wall). Luas permukaan lubang dihitung dengan persamaan:

$$
A_{\text {Lubang }}=\frac{1}{4} \pi \cdot d^{2} \text { (dihitung per lubang) }
$$

Perhitungan kehilangan tekanan pada lubang digunakan persamaan:

$$
h_{f}=k_{1} \frac{V^{2}}{2 g}+\frac{V_{2}}{2 g}
$$

\section{Zona outlet}

Air yang keluar dari bak pengendap keluar melalui ambang pelimpah (Weir) kemudian dialirkan ke pengolahan berikutnya. Tinggi air diatas pelimpah dihitung dengan rumus:

$Q=3,33 \cdot b \cdot H^{3 / 2}$ (british unit)

Tinggi saluran pelimpah:

$Q=2,49 \cdot b \cdot h^{3 / 2}$

\section{Metodologi}

Metode penelitian ini adalah dengan studi pustaka.

\section{IV.Pembahasan}

Air baku dari sungai dialirkan dengan pemompaan lewat pipa transmisi ke bak prasedimentasi partikel-partikel diskrit diendapkan secara gravitasi.

Jumlah bak minimum $=2$ buah

$\mathrm{V}_{0}=$ kecepatan mengendap dari partikel ideal $=0,08-0,1 \mathrm{~cm} /$ detik

$t_{d}=$ waktu pengendapan $=0,5-3$ jam

Kondisi aliran $\mathrm{N}_{\mathrm{RE}}<2000$ dan $\mathrm{N}_{\mathrm{Fr}}>10^{-5}$

$\mathrm{V}_{\mathrm{h}}=(10-18) \mathrm{V}_{0}$

Kedalaman air dalam bak $=0,8-4,5$ meter

Direncanakan:

Debit $(\mathrm{Q})=150 \mathrm{lt} / \mathrm{detik}=0,15 \mathrm{~m}^{3} / \mathrm{detik}$

Jumlah bak $=4$ buah (debit tiap bak 37,5 lt/detik)

Bak direncanakan dengan good performance (nilai $\mathrm{n}=1 / 3$ ), presentase pengendapan $80 \%$ (fig.25-6 halaman 25-14, Water and Wastewater Engineering, Fair G.M, Geyer J.C dan Okun D.A, volume 2)

Kecepatan mengendap partikel:

$\mathrm{v}_{0}=4,8 \times 10^{-4} \mathrm{~m} /$ detik

Kondisi aliran $\mathrm{N}_{\mathrm{RE}}<2000$ dan $\mathrm{N}_{\mathrm{Fr}}>10^{-5}$

$\mathrm{V}_{\mathrm{h}}=18 \mathrm{~V}_{0}$

Ruang lumpur berbentuk limas terpancung.

Dari grafik lengkung performance untuk bak pengendap pendahuluan (Prasedimentasi) dengan efisiensi $80 \%$ didapat:

$$
\frac{t}{t d}=\frac{V_{0}}{Q / A}=2,2
$$


Dengan menggunakan persamaan 1:

$$
\frac{y}{y_{0}}=1-\left(1+\frac{n V_{0}}{Q / A}\right)^{-1 / n}
$$

Maka:

$$
\begin{aligned}
& \frac{80}{100}=1-\left(1+\frac{1 / 3 V_{0}}{Q / A}\right)^{-3} \\
& \left(1+\frac{1 / 3 V_{0}}{Q / A}\right)^{3}=\frac{10}{2}=5 \\
& \left(\frac{1 / 3 V_{0}}{Q / A}\right)=1,71-1=0,7 \\
& \left(\frac{V_{0}}{Q / A}\right)=2,13 \quad \begin{array}{r}
0,1 \\
\mathrm{~V}_{0} \text { disain }=\frac{0,046 \mathrm{~cm} / \mathrm{detik}}{2,13} \quad 0,46 \mathrm{~cm} / \mathrm{detik} / \mathrm{m}^{2}
\end{array} \\
& \text { Beban permukaan }=0,046 \mathrm{c}
\end{aligned}
$$

Kedalaman bak diambil $=100 \mathrm{~cm}$

$t=\frac{100}{0,046}=2174$ detik

$\mathrm{V}_{\mathrm{h}}$ diambil $=12 \mathrm{~V}_{0}$

$\mathrm{V}_{\mathrm{h}}=12 \times 0,046=0,552 \mathrm{~cm} / \mathrm{detik}$

Panjang bak $(\mathrm{P})=\mathrm{V}_{\mathrm{h}} \times \mathrm{t}$

$=0,552 \times 2174$

$=1200 \mathrm{~cm} \cong 12$ meter

Luas permukaan $(A s)$

$\frac{t}{t d}=\frac{V_{0}}{Q / A}=2,13$

$\frac{Q}{A s}=\frac{0,1}{2,13}$

$Q=\frac{150 \text { liter } / \mathrm{det} i k}{4}=37,5$ liter $/ \mathrm{detik}$

$A s=\frac{37.500 \times 2,13}{0,1}=798.750 \mathrm{~cm}^{2} \cong$

$79,875 \mathrm{~m}^{2}$

Lebar bak, $(\mathrm{L})=\frac{79,875}{12}=6,70 \mathrm{~m}$
Kontrol aliran:

Pada temperatur $24^{0} \mathrm{C}=0,9186 \times 10^{-2}$ $\mathrm{cm}^{2} /$ detik agar aliran dalam bak laminer, maka:

$$
\begin{aligned}
& N_{\mathrm{Re}}=V h x \frac{R}{v} \leq 2000 \\
& N_{\mathrm{Re}}=0,552 x \frac{[(670 \times 100) /(670+200)]}{0,9186 \times 10^{-2}} \\
& N_{\mathrm{Re}}=462,77<2000 \rightarrow \text { (memenuhi) } \\
& N_{F r}=\frac{V h^{2}}{(g x R)} \geq 10^{-5} \\
& N_{F r}=\frac{(0,552)^{2}}{\{9,81 x(670 \times 100) /(670+200)\}} \\
& N_{F r}=0,4033 \times 10^{-5} \rightarrow \text { (memenuhi) }
\end{aligned}
$$

Kontrol $\mathrm{N}_{\mathrm{Re}}$ partikel:

$\mathrm{N}_{\mathrm{Re}}$ partikel $<0,5$ agar memenuhi hukum Stoke, yaitu:

$V s=V_{0} x d=0,046 \mathrm{~cm} /$ detik

maka digunakan persamaan 5 (Hukum Stoke):

$V s=\frac{1}{18}\left[\frac{(S s-1)}{\delta}\right] \cdot g \cdot d^{2}$

$0,046=\frac{1}{18}\left[\frac{(2,65-1)}{0,9186 \times 10^{-2}}\right] \cdot 981 \cdot d^{2}$

$d=0,0035 \mathrm{~cm}$

Jadi partikel yang terendapkan berdiameter $\geq$ $0,0035 \mathrm{~cm}$

$N_{\mathrm{Re}}=\frac{d x V s}{\delta}=\frac{0,0035 \times 0,046}{0,9186 \times 10^{-2}}=$

$0,017<0,5 \rightarrow$ (memenuhi hukum Stoke)

Kontrol terhadap kecepatan penggerusan digunakan persamaan 6 (Scouring):

$V_{S c}=\sqrt{\frac{8 \beta}{\lambda} \cdot \frac{\rho_{s}-\rho_{w}}{\rho_{w}} \cdot g . d}$

(L. Huisman, Sedimentation And Flotation), diambil rata - rata $=0,03$, jadi:

$V_{S c}=\sqrt{\frac{8(0,05)}{0,03} x \frac{2,65-1}{1} \times 981 x 0,0035}$

$V_{S c}=5,46 \mathrm{~cm} /$ detik

$V_{H}=0,552 \mathrm{~cm} /$ detik $<V_{S c}$ (tidak terjadi penggerusan) 
Maka dimensi bak prasedimentasi adalah:

Panjang $=12$ meter

Lebar $=6,7$ meter

Tinggi $=1$ meter $+0,50$ Freeboard

Ruang lumpur

Dari percobaan tabung Inhoff Cone prosentase pengendapan lumpur kasar selama 30 menit $=$ $0,2 \%$, terakumulir dalam ruang pengendap dan untuk ruang lumpur direncanakan 3 hari.

$V_{\text {Lumpur }}=Q x \%_{\text {Pengendapan }} x t_{B L}$

$V_{\text {Lumpur }}$

$=$

$Q_{\text {bak }}$ liter $/ \operatorname{det} i k x \%_{\text {Pengendapon }} x t_{\text {Waktupenyinpanan }}$ 1000liter

$V_{\text {Lumpur }}$

37,5liter / det ikx0,2\% x86400 det ix3hari 1000liter

$19,44 \mathrm{~m}^{3}$

Ruang lumpur berbentuk limas terbalik dibawah zona pengendapan.

$$
V_{\text {Luimas }}=\frac{1}{3} x t x A_{\text {Surface }} \rightarrow V_{\text {Lumpur }} \cong V_{\text {Luimas }}
$$

$$
\begin{aligned}
19,44 & =\frac{1}{3} x t x(6,7 \times 12) \\
t & =0,72 \mathrm{~m}, \text { jadi tinggi ruang lumpur } \\
& =75 \mathrm{~cm} \text { (dibulatkan) }
\end{aligned}
$$

Kecepatan aliran masuk pada saluran $(\mathrm{V})=60$ $\mathrm{cm} /$ detik.

Debit yang diolah, $\mathrm{Q}=150 \mathrm{l} / \mathrm{detik}=0,15$ $\mathrm{m}^{3} /$ detik.

Maka luas permukaan saluran, Acr:

$$
\text { Acr }=\frac{Q}{V}=\frac{0,15 \mathrm{~m}^{3} / \mathrm{det}}{0,60 \mathrm{~m} / \mathrm{det}}=2500 \mathrm{~cm}^{2}
$$

Lebar saluran ditentukan $=0,40 \mathrm{~m}$

Tinggi muka air pada saluran, $\mathrm{H}$ :

$$
H_{\text {Saluran }}=\frac{Q}{V x L e b a r}=\frac{0,15 \mathrm{~m}^{3} / \mathrm{det}}{0,60 \mathrm{~m} / \operatorname{det} x 0,4 \mathrm{~m}}=
$$

$0,625 \mathrm{~m} \cong 62,5 \mathrm{~cm}$

Kedalaman saluran $=H_{\text {Saluran }}+$ Freeboard

$=(62,5+12,5) \mathrm{cm}=75 \mathrm{~cm}$

Dimensi saluran $=(40 \times 75) \mathrm{cm}$
Pintu Air

Dari saluran utama air masuk ke bak prasedimentasi dengan satu buah pintu pada setiap unit prasedimentasi. Lebar pintu $60 \mathrm{~cm}$ dan bukaan $35 \mathrm{~cm}$. Koefisien pemerataan aliran $(m)=0,98$. Debit yang melalui pintu air setiap unit prasedimentasi adalah 37,5 liter/detik, maka kehilangan tekanan dihitung sebagai berikut:

Debit tiap bak prasedimentasi:

$\mathrm{Q}_{1}=\mathrm{Q}_{2}=\mathrm{Q}_{3}=\mathrm{Q} 4=\frac{150 \text { liter } / \mathrm{det}}{4}=37,5$

liter/detik

Kehilangan tekanan pada Pintu-1

$$
\begin{aligned}
h_{f(\mathrm{I})} & =\left(\frac{Q}{2,746 x b x h}\right)^{2} \\
& =\left(\frac{Q}{2,746 \times 0,6 \times 0,35}\right)^{2}
\end{aligned}
$$

$=0,42 \mathrm{~cm}$

Luas Pintu (Acr)

$Q=C \cdot A \cdot \sqrt{2 \cdot g \cdot h} \quad \rightarrow C=0,6$

$A c r=\frac{Q}{C \cdot \sqrt{2 \cdot g \cdot h_{1}}}$

$=\frac{37500}{0,6 \cdot \sqrt{2(981) 0,42}}$

$=2177 \mathrm{~cm}^{2}$

Kecepatan aliran (V)

$\mathrm{V}=C \cdot \sqrt{2 \cdot g \cdot h_{1}}$

$=0,6 \sqrt{2(981) 0,42}$

$=17,22 \mathrm{~cm} /$ deti $\mathrm{k}$

Kehilangan tekanan pada Pintu - 2

$h_{f}(\mathrm{II})=m^{2} x h_{f}(I)$

$=(0,98)^{2} \times 0,42 \mathrm{~cm}$

$=0,40 \mathrm{~cm}$

$Q=C \cdot A \cdot \sqrt{2 \cdot g \cdot h} \quad \rightarrow C=0,6$

$A c r=\frac{37500}{0,6 \cdot \sqrt{2(981) 0,84}}$

$=1539,54 \mathrm{~cm}^{2}$

Kecepatan aliran, (V) 


$$
\begin{aligned}
& \mathrm{V}=C \cdot \sqrt{2 \cdot g \cdot h_{2}} \\
& =0,6 \cdot \sqrt{2(981) 0,40} \\
& =16,81 \mathrm{~cm} / \text { detik }
\end{aligned}
$$

Sitem pemerataan aliran

Untuk pemerataan aliran yang masuk ke unit pra-sedimentasi digunakan perpoforated wall (dinding berlubang), diameter tiap lubang diambil $5 \mathrm{~cm}$ dengan perhitungan sebagai berikut:

$\phi_{\text {Lubang }}=5 \mathrm{~cm}$

$\mathrm{V}_{\mathrm{L}}=50 \mathrm{~cm} /$ detik $=0,5 \mathrm{~m} /$ detik (ditetapkan)

$A_{\text {Lubang }}=\frac{1}{4} \pi \cdot d^{2}$ (1 buah lubang) (persamaan

$=\frac{1}{4} \times 3,14(0,05)^{2}=1,9625 \times 10^{-3} \mathrm{~m}^{2}$

Debit air 1 lubang $\left(\mathrm{Q}_{\mathrm{L}}\right)$

$\mathrm{Q}_{\mathrm{L}}=\mathrm{V}_{\mathrm{L}}$ x $A_{\text {Lubang }}$

$=0,5 \times\left(1,9625 \times 10-^{-3}\right)$

$=9,812 \times 10^{-4} \mathrm{~m}^{3} /$ detik

sistem pelimpah (Weir)

Panjang Weir, $\left(\mathrm{P}_{\text {Weir }}\right)$

$\mathrm{P}_{\text {Weir }} \simeq \mathrm{L}_{\mathrm{Bak}}=6,70 \mathrm{~m}$

Beban Pelimpah, $\left(\mathrm{G}_{\mathrm{Wr}_{\mathrm{r}}}\right)$

$G_{W r}=\frac{37,5 \text { liter } / \text { det } i k}{6,7}$

$=5,6 \mathrm{l} / \mathrm{detik} / \mathrm{m}$

Rumus pelimpah (Weir):

$Q=3,33 \cdot b \cdot H^{3 / 2} \quad$ (british unit)

Dimana:

$\mathrm{Q}=37,5 \mathrm{l} / \mathrm{detik}=1,325 \mathrm{cfs}$

$\mathrm{b}=6,70 \mathrm{~m}=21,98 \mathrm{ft}$

Perhitungan:

$Q=3,33 \cdot b \cdot H^{3 / 2}$

$1,325=3,33 \times 21,98 x H^{3 / 2}$

$H=0,0689 \mathrm{ft}=2,135 \mathrm{~cm}$

Jadi:

Tinggi air di atas pelimpah $=2,135 \mathrm{~cm}$

Lebar saluran pelimpah direncanakan

$\mathrm{b}=30,48 \mathrm{~cm}=1,00 \mathrm{ft}$

$Q=2,49 \cdot b \cdot h^{3 / 2}$
Jumlah Lubang pada dinding perforated wall :

$=\frac{\frac{Q_{b a k}}{Q_{L}}}{=}=\frac{0,0375 \mathrm{~m}^{3} / \operatorname{det} k}{9,812 \times 10^{-4} \mathrm{~m}^{3} / \operatorname{det} i k}$

$=38$ buah

Luas total lubang, $A_{T L}$

$A_{T L}=38 \times 1,9625 \times 10^{-3} \mathrm{~m}^{2}$

$=0,075 \mathrm{~m}^{2}$

Kehilangan tekanan pada perforated wall, $\left(h_{f}\right)$

$h_{f}=k_{1} \frac{V^{2}}{2 g}+\frac{V_{2}}{2 g}$

$h_{f}=\frac{V^{2}}{2 g}(0,6+1)$

$=\frac{(50)^{2}}{2 \times 981}(0,6+1)=2,038 \mathrm{~cm}$

Sitem outlet

Outlet yang direncanakan menggunakan

$h=0,597 \quad \mathrm{ft} \quad=19,70 \mathrm{~cm} \rightarrow$ dibulatkan menjadi $20 \mathrm{~cm}$.

Jadi tinggi saluran $=20 \mathrm{~cm}+10 \mathrm{~cm}$ (freeboard)

Dimensi saluran penampang supernatant:

$=(30 \times 30) \mathrm{cm}$

\section{Kesimpulan}

Berdasarkan hasil perhitungan unit prasedimentasi diperoleh kesimpulan sebagai berikut:

1. Bak Prasedimentasi terdiri dari 4 unit bak

2. Pembuangan lumpur dilakukan setiap 3 hari.

3. Dimensi bangunan bak Prasedimentasi:

Panjang $=12$ meter

Lebar $=6,70$ meter

Tinggi $=1$ meter

Tinggi ruang lumpur $=0,75$ meter 
R. Esther Ambat, R.Andjar Prasetyo

\section{Daftar Pustaka}

Benny,C. Sistem Penyediaan Air Minum (Bahan Diklat Perpamsi ITB angkatan X), Lembaga Pengabdian Masyarakat ITB - PERPMASI. Bandung.

Fair, G.M,. Geyer, J.C dan Okun, D.A Gordon Waste Water and Engineering, volume 2 .

L.Huisman,. Sedimentation and floatation Mechanical Filtration", Delf University of Technology.

M. Annis, A. Shamim, Middlebroks, EJ. Water Supply Engineering Design, Ann Arbor Science. 